\title{
TGF- $\beta 1$ induces peritoneal fibrosis by activating the Smad2 pathway in mesothelial cells and promotes peritoneal carcinomatosis
}

\author{
ZHI-DONG LV, HAI-BO WANG, FU-NIAN LI, LI WU, CHEN LIU, GANG NIE, \\ BIN KONG, HUI-LI QU and JIAN-GUO LI
}

Department of Breast Surgery, The Affiliated Hospital of Qingdao University Medical College, Qingdao 266003, P.R. China

Received September 24, 2011; Accepted October 31, 2011

DOI: $10.3892 / \mathrm{ijmm} .2011 .852$

\begin{abstract}
Peritoneal dissemination is one of the main causes of death in gastric cancer patients. Our previous study demonstrated that peritoneal fibrosis induced by transforming growth factor- $\beta 1$ (TGF- $\beta 1$ ) may provide a favorable environment for the dissemination of gastric cancer. The role of Smad3 in the development of dermal fibrosis, subcapsular cataract, and peritoneal fibrosis has been reported. However, the potential role of $\mathrm{Smad} 2$ in the development of fibrosis is unclear. The objective of this study was to determine the effect of Smad2 in peritoneal fibrosis, induced by TGF- $\beta 1$, on dissemination of gastric cancer. Here we demonstrate that TGF- $\beta 1$ significantly stimulated the expression of collagen III and fibronectin in mesothelial cells through the Smad2 signal transduction pathway, but knockdown of the Smad2 gene by silencing siRNA partially inhibited these effects. This inhibition was associated with a depressed adhesion and invasiveness of gastric cancer cells. We conclude that peritoneal fibrosis induced by TGF- $\beta 1$ is dependent on Smad2 signaling and may provide a hospitable environment for carcinomatosis.
\end{abstract}

\section{Introduction}

Peritoneal carcinomatosis remains a major obstacle that severely limits the further improvement of gastric cancer patients' prognosis after surgeries (1). It appears in the terminal stage and significantly worsen the prognosis of this type of gastric carcinoma (2). Thus, the presence or absence

Correspondence to: Dr Jian-Guo Li, Department of Breast Surgery, The Affiliated Hospital of Qingdao University Medical College, Qingdao 266003, Shandong Province, P.R. China

E-mail: houjibofa20080808@163.com

Abbreviations: HPMCs, human peritoneal mesothelial cells; TGF- $\beta 1$, transforming growth factor- $\beta 1$; ECM, extracellular matrix

Key words: peritoneal fibrosis, peritoneal carcinomatosis, transforming growth factor- $\beta 1$, human peritoneal mesothelial cells, Smad2 of peritoneal metastasis after surgery is one of the most critical factors in determining the prognosis of patients with gastric cancer. Unfortunately, little is known about the mechanism of this phenomenon.

Stephen Paget's 'seed and soil' theory of tumor metastasis may provide a clue useful for further investigation. This theory stated that the sites where metastasis occurs are defined not only by the tumor cells (seed) but also by the local microenvironment of the metastatic site (soil) (3). In other words, the specific site of cancer cell metastasis is not simply due to the anatomic location of the primary tumor or proximity to secondary sites but rather, it involves interactions between tumor cells and the local microenvironment at the secondary site (4). Therefore, peritoneal carcinomatosis may occur as the peritoneal stroma environment promotes tumor cells to attach to the peritoneal mesothelium by providing various growth factors and chemokines that promote tumor metastasis (5). This process is established by the interactions between extracellular matrix-associated proteins and signals produced by mesothelial cells and the corresponding adhesion molecules from tumor cells (6). Extracellular matrix (ECM) components such as collagen, laminin, fibronectin and hyaluronic acid are ligands for integrins and CD44h, which are thought to be involved in the peritoneal dissemination of cancer cells (7).

Transforming growth factor- $\beta 1$ (TGF- $\beta 1)$ is a $25 \mathrm{kD}$ homodimeric polypeptide that can participate in a broad array of biologic activities such as normal development, wound healing and pathological processes (8). TGF- $\beta 1$ is also an inducer of ECM protein synthesis and has been implicated as the key mediator of fibrogenesis in various tissues $(9,10)$. Our previous study demonstrated that the TGF- $\beta 1$ levels in peritoneal lavage fluid are significantly correlated with peritoneal metastasis and TNM stages of gastric cancer $(11,12)$. In addition, peritoneal fibrosis induced by TGF- $\beta 1$ stimulates adhesion of gastric cancer cells to the peritoneum, thus resulting in an increase of the potential for peritoneal dissemination (12-14). However, the mechanisms are not yet clearly understood. In the present study we demonstrate in vitro that TGF- $\beta 1$ involvement in peritoneal fibrosis occurs through Smad2 signaling, and is dependent on microenviroment changes in the ability of gastric cancer cells to attach to and invade through mesothelial cells in the early stages of peritoneal dissemination. 
Table I. Primers used in the RT-PCR analysis.

\begin{tabular}{|c|c|c|}
\hline Primer & Sequence & Length (bp) \\
\hline Collagen III & $\begin{array}{ll}\mathrm{F} & 5^{\prime} \text {-GGACCACCAGGGCCTCGAGGTAAC-3' } \\
\mathrm{R} & \text { 5'-TGTCCACCAGTGTTTCCGTG-3' }\end{array}$ & 471 \\
\hline Fibronectin & $\begin{array}{ll}\mathrm{F} & 5^{\prime} \text {-TGGACCTTCTACCAGTGCGAC-3' } \\
\mathrm{R} & 5^{\prime} \text {-TGTCTTCCCATCATCGTAACAC-3' }\end{array}$ & 451 \\
\hline$\beta$-actin & $\begin{array}{ll}\mathrm{F} & \text { 5'-CCTCGCCTTTGCCGATCC-3' } \\
\mathrm{R} & \text { 5'-GGATCTTCATGAGGTAGTCAGTC-3' }\end{array}$ & 626 \\
\hline
\end{tabular}

\section{Materials and methods}

Total Smad2, phosphorylated Smad2, fibronectin and collagen III antibodies, as well as secondary antibodies were purchased from Santa Cruz Biotechnology, Inc. (USA). Calcein-AM was obtained from Calbiochem, UK. Dulbecco's modified Eagle's medium and fetal calf serum (FCS) were purchased from Gibco-BRL (USA). Human TGF- $\beta 1$ was obtained from Sigma (USA), human TGF- $\beta 1$ ELISA kit from R\&D Systems (Minneapolis, MN, USA), a phase contrast microscope from Nikon Japan, and a fluorescence microscope from Japan Olympus (Japan). Other laboratory reagents were obtained from Sigma (USA).

Cells and culture. Mesothelial cells were isolated from surgical specimens of human omentum as previously described (15). Briefly, small pieces of omentum were surgically resected under sterile conditions and were trypsinized at $37^{\circ} \mathrm{C}$ for 30 $\min$. The suspension was then passed through a $200-\mu \mathrm{m}$-pore nylon mesh to remove undigested fragments and centrifuged at 2,000 rpm for $5 \mathrm{~min}$. The collected cells were cultured in RPMI-1640 supplemented with 10\% FCS. In the following experiments, cells were used during the second or third passage after primary culture. Human peritoneal mesothelial cells (HPMCs) were identified by immunostaining with mouse monoclonal antibodies against cytokeratin and vimentin (DAKO, Japan). The donors had no signs of peritoneal inflammation and/or malignancy. All patients provided written informed consent prior to participation in the study. Our study was approved by the institutional ethics committee. An undifferentiated human gastric carcinoma cell line, HGC-27, was obtained from the Cancer Research Institute of Beijing, China. This cell lines was cultivated in T75 tissue culture flasks in DMEM supplemented with $10 \%$ fetal calf serum, $100 \mathrm{U} / \mathrm{ml}$ penicillin, $100 \mu \mathrm{g} / \mathrm{ml}$ streptomycin, $2 \mathrm{mM} \mathrm{L}$-glutamine, and $20 \mathrm{mM}$ hydroxyethyl piperazine ethanesulfonic acid (HEPES). Cultures were grown at $37^{\circ} \mathrm{C}$ in a humidified $5 \% \mathrm{CO}_{2}$ and $95 \%$ air incubator.

Semi-quantitative reverse transcription polymerase chain reaction (RT-PCR). The cells were grown to subconfluence and then starved for $15 \mathrm{~h}$ in serum-free medium to attain quiescence. Afterwards, the cells were washed twice with PBS and cultured in either serum-free medium (control) or serum-free medium plus $5 \mathrm{ng} / \mathrm{ml}$ of TGF- $\beta 1$ (experimental) for up to $72 \mathrm{~h}$. Total-RNA was isolated from these cells using the TRIzol reagent according to the manufacturer's instructions. One microgram of the total cellular RNA was then reverse-transcribed into cDNA for PCR amplification using a kit from Sigma. The primer sequences used for PCR are listed in Table I. Amplification consisted of an initial $5 \mathrm{~min}$ incubation at $95^{\circ} \mathrm{C}$ and then 30 cycles of amplification using $30 \mathrm{sec}$ of denaturation at $95^{\circ} \mathrm{C}, 30 \mathrm{sec}$ at $56^{\circ} \mathrm{C}$ and $60 \mathrm{sec}$ at $72^{\circ} \mathrm{C}$. The final extension was set for $10 \mathrm{~min}$ at $72^{\circ} \mathrm{C}$. All data were expressed as the relative differences between control and treated cells after normalization to $\beta$-actin expression.

Protein extraction and Western blotting. Total cellular protein was extracted using a lysis buffer and quantified using protein quantification reagents from Bio-Rad. Next, $50 \mu \mathrm{g}$ of the protein were suspended in $5 \mathrm{X}$ reducing sample buffer, boiled for $5 \mathrm{~min}$, electrophoresed on 10\% SDS-PAGE gels, and then transferred to polyvinylidene difluoride membrane by electroblotting. The membrane was blocked in $1 \% \mathrm{BSA} / 0.05 \%$ Tween/ PBS solution overnight at $4^{\circ} \mathrm{C}$, followed by incubation with the primary antibody for $24 \mathrm{~h}$. A horseradish peroxidase-labelled goat anti-mouse $\operatorname{IgG}$ was used as the secondary antibody. The blots were then developed by incubation in a chemiluminescence substrate and exposed to X-ray films.

Enzyme-linked immunoassay (ELISA). Culture media were analyzed for collagens type III and fibronectin using sandwich ELISA. HPMCs were cultured on a 6-well tissue culture plate to confluence. The cells were treated with recombinant human TGF- $\beta 1$ once i.e. at the time of switching to serumfree medium for a specific period, and then was changed the medium. After $24 \mathrm{~h}$, the culture medium was harvested. Purified human collagen III and fibronectin were used as a standard. Manipulation was performed according to the manufacturer's instructions. The data on the collagen III and fibronectin protein levels were summarized as mean \pm SE of each sample.

Immunofluorescence staining. The expression of fibronectin in mesothelial cells was analyzed by immunofluorescence microscopy. In brief, the cells were cultured on collagen-coated glass coverslips up to confluency and then fixed in $4 \%$ paraformaldehyde in $20 \mathrm{mM}$ HEPES (pH 7.4) and $150 \mathrm{mM} \mathrm{NaCl}$ for $20 \mathrm{~min}$. The glass coverslips were rinsed three times and then permeabilized with $1.2 \%$ Triton X-100 for 5 min, rinsed three times again and then incubated with $1 \%$ BSA $/ 0.05 \%$ Tween/PBS for $1 \mathrm{~h}$. Staining for the expression of fibronectin 

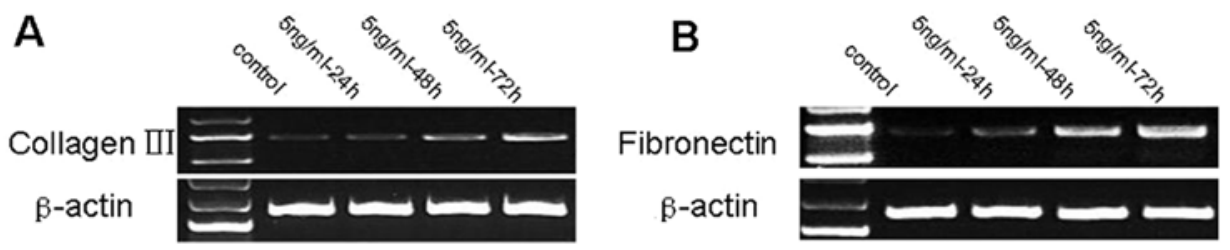

Figure 1. Effects of TGF- $\beta 1$ on collagen III and fibronectin mRNA expression in human peritoneal mesothelial cells (HPMCs). Serum-starved HPMCs were incubated with TGF- $\beta 1(5 \mathrm{ng} / \mathrm{ml})$ for 24,48 and $72 \mathrm{~h}$. The cells were harvested and processed for RT-PCR. The levels of $\beta$-actin expression were used as control. (A) Time response of collagen III mRNA expression. (B) Time response of fibronectin mRNA expression.
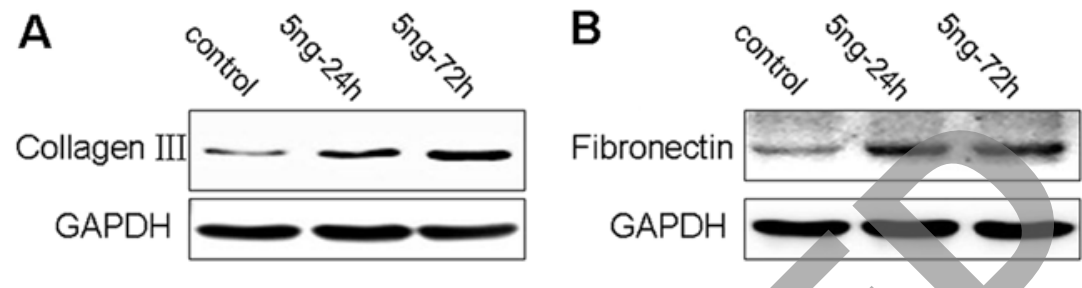

Figure 2. Effects of TGF- $\beta 1$ on collagen III and fibronectin protein expression in human peritoneal mesothelial cells (HPMCs). Serum-starved HPMCs were incubated with TGF- $\beta 1(5 \mathrm{ng} / \mathrm{ml})$ at various time points. The cells were harvested and processed for Western blotting. The levels of GAPDH expression were used as control. (A) Time response of collagen III expression. (B) Time response of fibronectin expression.

was carried out with a primary rabbit anti-fibronectin (1:200) antibody and then with a secondary antibody conjugated with FITC. The DNA dye TO-PRO-3 (blue) was used for counterstaining. The stained cells were mounted and viewed under immunofluorescence microscopy.

Small interfering-RNA (siRNA) treatment. The HPMCs were grown to $70 \%$ confluence on culture dishes and the transient transfection was performed with specific stealth small interference RNA (siRNA) against Smad2, or control siRNA overnight using Lipofectamine 2000 (Invitrogen; Carlsbad, CA), according the manufacturer's instructions. The total of three siRNA sequences for $S \operatorname{mad} 2$ and control-siRNA were designed and synthesized from Invitrogen using an RNAi designer software program. The concentration of $300 \mathrm{nM}$ was determined to be the most effective siRNA concentration for Smad2 silencing. The transfection medium was changed with culture medium containing 5\% FBS for $24 \mathrm{~h}$. TGF- $\beta 1$ at a final concentration of $5 \mathrm{ng} / \mathrm{ml}$ was added to the cell cultures in serum-free medium with or without TGF- $\beta 1$ (control). The cells were harvested at 4, 24 and $72 \mathrm{~h}$ for further experiments.

Tumor cell adhesion assay. The adhesion ability of gastric cancer cells to mesothelial cells was determined as described previously by Alkhamesi et al (16). Briefly, HPMCs were grown in a monolayer in 96-well plates overnight and treated with TGF- $\beta 1$ or Smad2 siRNA. Cancer cells were stained with $15 \mu \mathrm{M}$ of calcein $\mathrm{AM}$ for $30 \mathrm{~min}$ at $37^{\circ} \mathrm{C}$ and $5 \% \mathrm{CO}_{2}$. Afterwards, these cells $\left(5 \times 10^{4} /\right.$ well) were added to 96 -well plates that contained peritoneal mesothelial cells and incubation occurred for $3 \mathrm{~h}$ at $37^{\circ} \mathrm{C}$. The plates were then washed three times with $200 \mu \mathrm{l}$ of growth medium to remove the non-adherent tumor cells. The remaining adherent tumor cells were observed under a fluorescence microscope. The reason for use of $3 \mathrm{~h}$ was based on our pre-run experiments of the kinetics of binding of cancer cells to cell culture dishes.
Invasion assay. The assay of in vitro invasiveness was carried out by the method of Hirashima et al (17). An invasion assay upper chamber with an $8.0-\mu \mathrm{m}$ porosity cell-permeable polycarbonate filter covered with Matrigel was placed on a cell culture plate. HPMCs were cultured fully on Matrigel, pretreated with TGF- $\beta 1$ or Smad2-siRNA, and washed, and gastric cancer cells HGC-27 were serum-starved for $12 \mathrm{~h}$ and then plated in the upper well at a concentration of $3 \times 10^{5} / \mathrm{ml}$ of serum-free medium. As a chemoattractant, $10 \%$ FCS medium was used in lower chamber. At the end of the incubation, the filters were removed, fixed in $95 \%$ alcohol, and stained with trypan blue. The cells remaining on the top surface of the membrane were completely removed with a cotton swab, and the membrane was removed from the chamber and mounted on a glass slide. The number of infiltrating cancer cells were counted in five regions selected at random, and the extent of invading cancer cells was determined by the mean count.

Statistical analysis. Data are expressed as mean \pm SD. Statistical comparisons of the data from the various groups were performed by using Student's t-test. Differences between groups were considered statistically significant at $\mathrm{P}<0.05$.

\section{Results}

TGF- $\beta 1$ up-regulates collagen III and fibronectin $m R N A$ expression in HPMCs. TGF- $\beta 1$ significantly increased steadystate levels of both collagen III and fibronectin mRNA in HPMCs (Fig. 1). The respective values of collagen III and fibronectin mRNA expression were 1.6- and 1.9-fold that of control at $48 \mathrm{~h}$, and were lower to those at $72 \mathrm{~h}$.

Effects of TGF- $\beta 1$ on collagen III and fibronectin protein production by HPMCs. To confirm that TGF- $\beta 1$ up-regulates collagen III and fibronectin protein expression in HPMCs we performed immunoblot analysis. TGF- $\beta 1$ increased collagen III and fibronectin production by HPMCs after $48 \mathrm{~h}$ 
A

\begin{tabular}{cccc}
\hline TGF- $\beta$ 1 & Ong/ml & $5 \mathrm{ng} / \mathrm{ml}$ & $10 \mathrm{ng} / \mathrm{ml}$ \\
\hline $24 \mathrm{~h}$ & $1.81 \pm 0.24$ & $3.66 \pm 0.42$ & $5.56 \pm 0.87$ \\
$48 \mathrm{~h}$ & $2.17 \pm 0.31$ & $5.19 \pm 0.77$ & $7.74 \pm 0.71$ \\
$72 \mathrm{~h}$ & $2.59 \pm 0.27$ & $6.67 \pm 0.67$ & $9.22 \pm 1.12$ \\
\hline
\end{tabular}

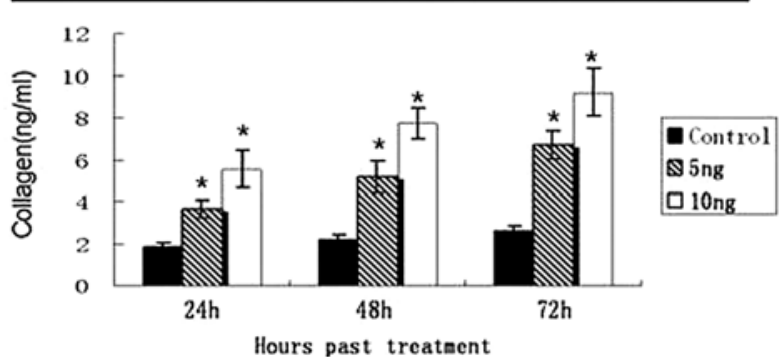

B

\begin{tabular}{cccc}
\hline TGF- $\beta$ 1 & Ong/ml & $5 \mathrm{ng} / \mathrm{ml}$ & $10 \mathrm{ng} / \mathrm{ml}$ \\
\hline $24 \mathrm{~h}$ & $35.03 \pm 7.47$ & $108.58 \pm 18.25$ & $175.57 \pm 18.64$ \\
$48 \mathrm{~h}$ & $48.30 \pm 8.15$ & $134.60 \pm 17.40$ & $207.48 \pm 21.10$ \\
$72 \mathrm{~h}$ & $56.48 \pm 8.07$ & $154.42 \pm 22.32$ & $263.23 \pm 17.78$ \\
\hline
\end{tabular}

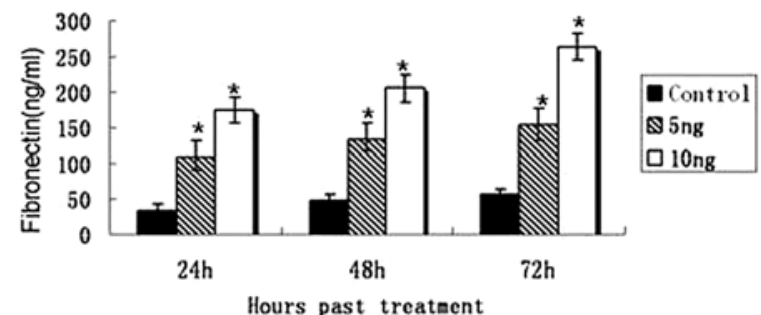

Figure 3. Effects of TGF- $\beta 1$ on collagen III and fibronectin secretion in conditioned media. Human peritoneal mesothelial cells (HPMCs) were incubated with several concentrations of TGF- $\beta 1$ for 24,48 and $72 \mathrm{~h}$. Concentrations of collagen III and fibronectin in conditioned media were determined using ELISA. Each bottom panel depicts the relative increase as the mean \pm standard error of the mean of at least 3 separate experiments. ${ }^{*} \mathrm{P}<0.05$ as compared with the control.

A

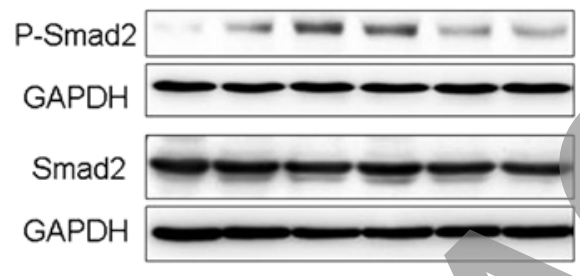

Control $15 \min 30 \mathrm{~min} 1 \mathrm{~h} \quad 3 \mathrm{~h} 24 \mathrm{~h}$

TGF- $\beta 1(5 \mathrm{ng} / \mathrm{ml})$
B

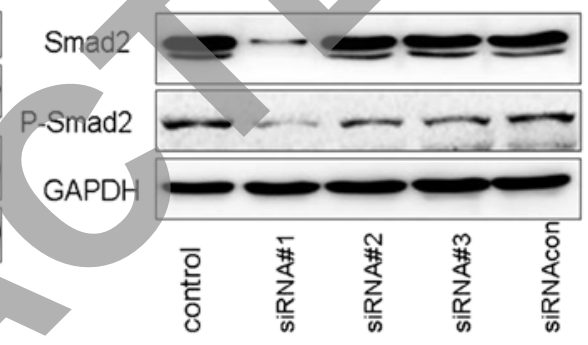

Figure 4. Smad2 siRNA suppresses the expression of Smad2 in TGF- $\beta 1$ activated human peritoneal mesothelial cells (HPMCs). (A) The HPMCs were incubated in the presence of TGF- $\beta 1(5 \mathrm{ng} / \mathrm{ml})$ for an indicated period of time or left untreated. Whole cell lysates were obtained and analyzed for phosphorylated forms of Smad2 and Smad2. Smad2 transcription factor phosphorylation was noted up to 30 min and it decreased at $24 \mathrm{~h}$. The expression of total Smad2 remained unchanged in control HPMCs and TGF- $\beta 1$-treated HPMCs. (B) HPMCs was transfected with siRNA Smad 2 and activated with TGF- $\beta 1$ for $4 \mathrm{~h}$ the transfection efficiency was confirmed. Three specific siRNA for Smad2 along with a control siRNA were used. siRNAi-Smad2\#1 showed highly significant knockdown for Smad2 and phosphorylated Smad2 when compared to the other two siRNA's or the control siRNA. GAPDH were used as a loading control to demonstrate equal protein loading. Results are the representative of three separate experiments.

of incubation in a time-dependent manner. ELISA confirmed the significant increase in collagen III and fibronectin protein synthesis in a dose- and time-dependent manner (Fig. 3).

Effects of TGF- $\beta 1$ or siRNAi-Smad2 on Smad2 phosphorylation of HPMCs. We examined the effect of TGF- $\beta 1$ on the activation of Smad 2 phosphorylation and total-Smad 2 in HPMCs. Here we show that $5 \mathrm{ng} / \mathrm{ml}$ of TGF- $\beta 1$ induced phosphorylation of Smad2 within 10 min of stimulation, and the level of Smad2 phosphorylation reached a maximum between 30-60 min after treatment and remained elevated for the duration of the experiment without affecting total Smad2 expression (Fig. 4A). In order to confirm whether Smad 2 is involved in TGF- $\beta 1$ mediated peritoneal fibrosis, siRNAs were used to knock down the Smad2 gene in HPMCs. siRNAi-Smad2\#1 showed highly significant knockdown for Smad 2 and phosphorylated Smad 2 when compared to the other two siRNA's or control siRNA (Fig. 4B).

Silencing Smad2 signaling blocks TGF- $\beta 1$ induced collagen III and fibronectin expression in HPMCs. In order to confirm that Smad2 is involved in TGF- $\beta 1$ induced collagen III and fibro- nectin expression in HPMCs, siRNAs were used to knock down the Smad2 gene in HPMCs. We first evaluated the expression of collagen III and fibronectin in total cell lysates by Western blot analysis, after silencing Smad2 by using siRNA-Smad2 or control-siRNA in HPMCs treated with TGF- $\beta 1$. Treatment of HPMCs with siRNA-Smad 2 prior to TGF- $\beta 1$ stimulation significantly inhibited the expression of collagen III and fibronectin when compared to control (Fig. 5A and B). We also examined the expression of fibronectin by immunofluorescence staining. Fibronectin fibrils were clearly detected in the cytoplasmic region of HPMCs treated with TGF- $\beta 1$ at $48 \mathrm{~h}$, but HPMCs were transfected with siRNA-Smad 2 showed minimal fibronectin deposition (Fig. 5C).

Induction of gastric cancer cell adhesion to the mesothelial cells through peritoneal fibrosis. We then assessed the role of TGF- $\beta 1$ and Smad 2 siRNA in regulating the adhesion ability of gastric cancer cells to mesothelial cells. By fluorescently examining the level of tumor cells adhering to mesothelial cells in response to TGF- $\beta 1$ treatment, we found that peritoneal fibrosis appeared to be able to promote gastric cancer cell 

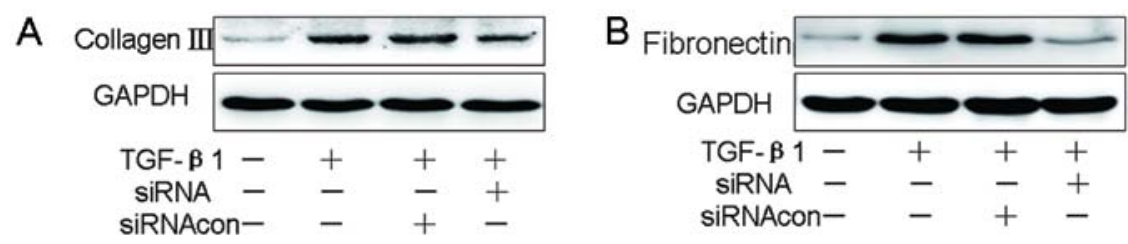

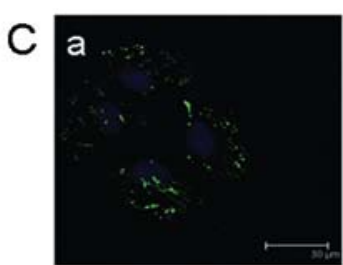

TGF- $\beta 1$

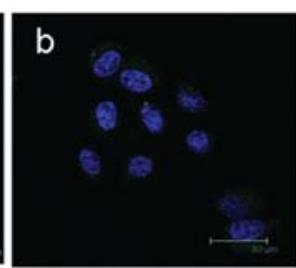

TGF- $\beta 1+$ siRNA

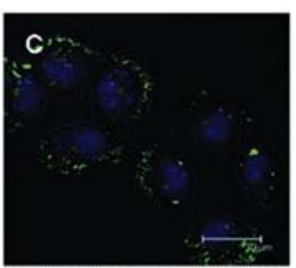

TGF- $\beta 1+$ siRNA-con

Figure 5. Collagen III and fibronectin mRNA and protein levels in human peritoneal mesothelial cells (HPMCs). (A) The levels of collagen III and fibronectin mRNA expression was evaluated by RT-PCR. HPMCs were transfected with siRNA-Smad 2 or control siRNA and treated with TGF- $\beta 1$ for $72 \mathrm{~h}$. Smad 2 siRNA transfection suppresses collagen III and fibronectin mRNA in TGF- $\beta 1$ treated HPMCs. (B) Western blot analysis of collagen III and fibronectin protein levels in HPMCs, HPMCs were transfected with siRNA-Smad2 or control siRNA and treated with TGF- $\beta 1$ for $72 \mathrm{~h}$. Smad2 siRNA transfection suppresses collagen III and fibronectin protein expression in TGF- $\beta 1$-treated HPMCs. (C) Immunofluorescence staining for fibronectin (green) was evaluated by fluorescence microscopy. TGF- $\beta 1$-treated HPMCs showed up-regulated fibronectin expression. HPMCs transfected with siRNA-Smad2 showed low fibronectin deposition. Scale bar, $30 \mu \mathrm{m}$.

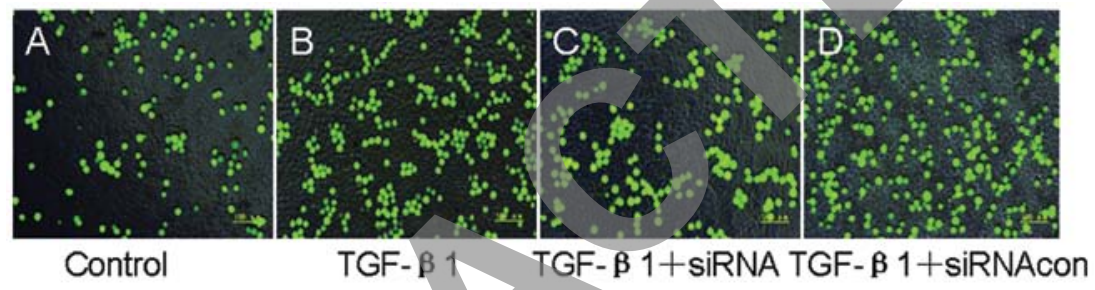

Figure 6. Effects of peritoneal fibrosis on cancer cell adhesion to mesothelial cells. Fluorescently-labeled gastric carcinoma cells were overlaid on mesothelial cells and incubated at $37^{\circ} \mathrm{C}$ for $3 \mathrm{~h}$. After gentle washing to remove nonadherent cells, the adherent cells were measured with optic-fluorescence microscopy. For the inhibition experiment, the human peritoneal mesothelial cells (HPMCs) were (A) untreated as a control; (B) treated with TGF- $\beta 1$ (5 ng/ml) for $72 \mathrm{~h}$; (C) transfected with siRNA-Smad2 and treated with TGF- $\beta 1$ for $72 \mathrm{~h}$; (D) transfected with control siRNA and treated with TGF- $\beta 1$ for $72 \mathrm{~h}$ before the incubation with peritoneum. The assays were carried out in tríplicate. Scale bar, $100 \mu \mathrm{m}$.

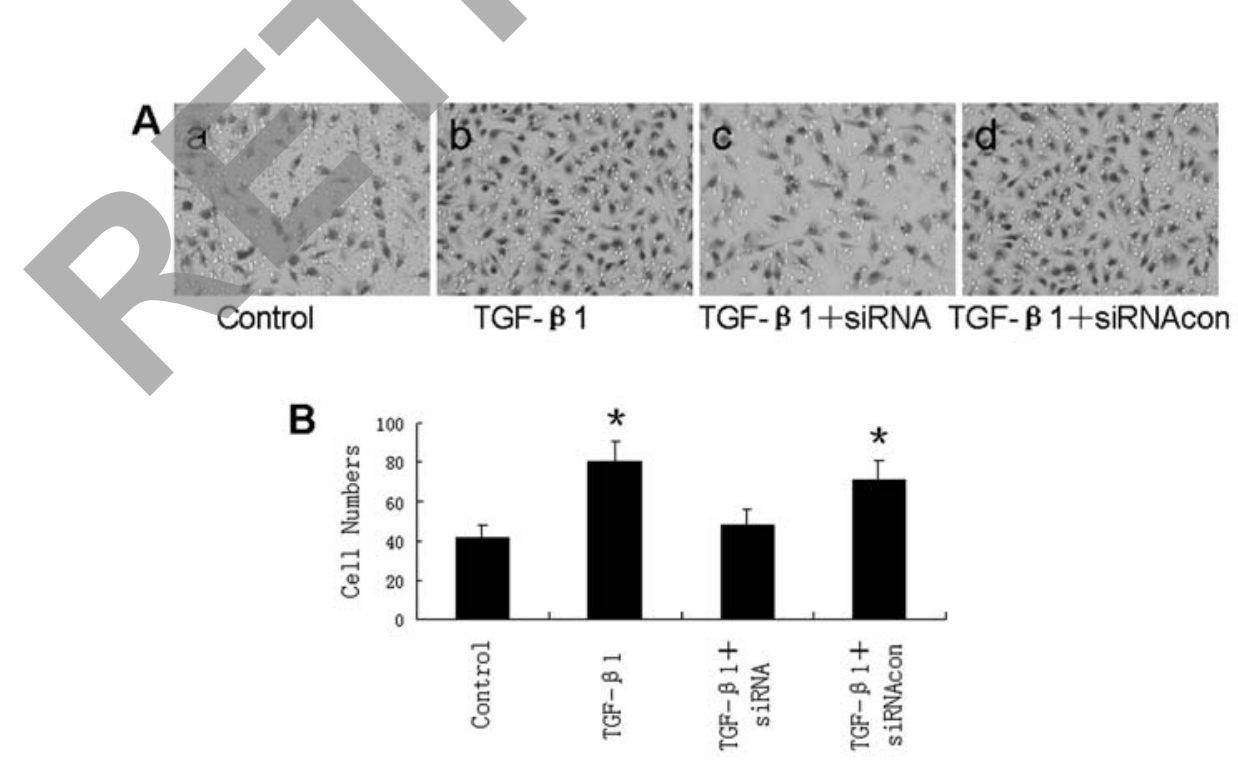

Figure 7. Effects of peritoneal fibrosis on cancer cell invasion through mesothelial monolayers. (A) Gastric carcinoma cells were overlaid on mesothelial cells and incubated at $37^{\circ} \mathrm{C}$ for $18 \mathrm{~h}$. The infiltrating cancer cells were fixed in $95 \%$ alcohol, and stained with trypan blue. For the inhibition experiment, human peritoneal mesothelial cells (HPMCs) cells were (a) untreated as a control; (b) treated with TGF- $\beta 1$ ( $5 \mathrm{ng} / \mathrm{ml}$ ) for $72 \mathrm{~h}$; (c) transfected with siRNA-Smad2 and treated with TGF- $\beta 1$ for $72 \mathrm{~h}$; (d) transfected with control siRNA and treated with TGF- $\beta 1$ for $72 \mathrm{~h}$, before the incubation with peritoneum. (B) The assays were carried out in triplicate. $\mathrm{P}<0.05$ as compared with control ( $\mathrm{x} 40)$.

adherence to mesothelial cells, as compared to the control. Smad2 siRNA decreased the number of cancer cells that adhered to the mesothelial cells under TGF- $\beta 1$ stimulation (Fig. 6). 
Induction of gastric cancer cell invasion through mesothelial monolayers through peritoneal fibrosis. To investigate the potential of peritoneal fibrosis in promoting gastric cancer cell invasion through mesothelial monolayers, we used HGC-27 cell lines in Transwell invasion assays. After $18 \mathrm{~h}$ of incubation for invasion, the wells were harvested and cells that migrated to the lower surface of the membrane were counted. The peritoneal fibrosis microenvironment significantly promoted the invasiveness of cells (Fig. 7). Smad2-siRNA decreased the number of cancer cells that invaded through mesothelial monolayers under TGF- $\beta 1$ stimulation.

\section{Discussion}

In $40-50 \%$ of patients with gastric cancer, the cancer recurs, most frequently in the form of peritoneal metastasis, even after potentially curative resection $(18,19)$. Paget has explained this phenomenon by the 'seed and soil' theory: metastases occur when some tumor cells only live and grow in a congenial environment (3). Peritoneal fibrosis induced by gastric cancer cells, may be a congenial environment ('soil') for peritoneal metastases of gastric carcinoma. Our previous study demonstrated that the TGF- $\beta 1$ level in peritoneal lavage fluid is significantly correlated with peritoneal metastasis of gastric cancer (11). So we hypothesized that the abdominal cavity of cancer cells, dropping from primarily focus, released the early inflammatory factors, such as TGF- $\beta 1$, which induce peritoneal fibrosis. Contrarily, the peritoneal fibrosis may stimulate dissemination of gastric cancer.

Fibronectin and collagen are ubiquitous constituents of the ECM. Secreted by cells as a soluble dimer, it is then processed and assembled into insoluble fibrils at the cell surface $(20,21)$. It has been demonstrated that fibronectin released by peritoneal mesothelial cells stimulates ovarian cancer cell motility in vitro $(6,20)$. Moreover, competitive inhibition of fibronectin by RGD-containing peptides has been reported to decrease peritoneal spreading of ovarian cancer cells in mice $(22,23)$. More recently it has been demonstrated that the attachment of cancer cells to the peritoneum results in up-regulation of their matrix metalloproteinase-2, which cleaves mesothelial cellderived fibronectin into small fragments that further augment cancer cell binding (24). Our present study demonstrates that TGF- $\beta 1$ up-regulates fibronectin and collagen III protein synthesis by HPMCs, which may contribute to peritoneal dissemination of gastric cancer.

Smads are a group of intracellular proteins that are critical for transmitting the TGF- $\beta 1$ signals from the cell surface to the nucleus to promote transcription of target genes $(25,26)$. The role of Smad3 in the development of dermal fibrosis, subcapsular cataract, and peritoneal fibrosis has been reported $(27,28)$. However, the potential role of Smad2 in the development of fibrosis is unclear. In the present study we demonstrate in vitro that the $\mathrm{Smad} 2$ signaling pathway may also be involved in peritoneal fibrosis, and silencing of Smad 2 blocks the effect of TGF- $\beta 1$. The TGF- $\beta 1$-induced peritoneal fibrosis is dependent on Smad2 signaling, thus suggesting the possibility that HPMCs may be the source of ECM, and provide a favorable environment for the dissemination of gastric cancer.

To investigate whether the introduction of TGF- $\beta 1$ could enhance tumor-mesothelial adhesion and if Smad2 siRNA could reduce this adhesion, we incubated the mesothelial cells with TGF- $\beta 1$, or with Smad2 siRNA and with TGF- $\beta 1$. In a subsequent step, we added tumor cells for three hours to evaluate the adhesion ability to mesothelial cells under various conditions. Interestingly, TGF- $\beta 1$ increases tumor-mesothelial adhesion. Consistently, the inhibition of TGF/Smad 2 pathway by siRNA led to a significant decrease of tumor-mesothelial adhesion. The findings are consistent with a previous report that TGF- $\beta 1$ may enhance tumor-mesothelial cell adhesion $(11,29,30)$.

We elucidated the influence of TGF- $\beta 1$ or Smad2-siRNA treated mesothelial cells on gastric cell invasion. Treatment of mesothelial cells with TGF- $\beta 1$ increased the gastric cell invasion as compared with the control. However, the effect of TGF- $\beta 1$ on tumor cell invasion was inhibited with Smad2siRNA. Taken together, peritoneal fibrosis induced by TGF- $\beta 1$ could modulate gastric cell cell adhesion to and invasion through mesothelial cell layers, and Smad2 were necessary for the effect.

In conclusion, TGF- $\beta 1$ increased the expression of collagen III and fibronectin of mesothelial cells, which was associated with the increased adhesive and invasion abilities of gastric cancer cells; while blocking Smad2 can partially inhibit these effects. These results indicated that peritoneal fibrosis induced by TGF- $\beta 1$ is dependent on $\operatorname{Smad} 2$ signaling and provide a hospitable environment for carcinomatosis.

\section{References}

1. Al-Shammaa HA, Li Y and Yonemura Y: Current status and future strategies of cytoreductive surgery plus intraperitoneal hyperthermic chemotherapy for peritoneal carcinomatosis. World J Gastroenterol 14: 1159-1166, 2008.

2. Parkin DM, Bray F, Ferlay J and Pisani P: Global cancer statistics, 2002. CA Cancer J Clin 55: 74-108, 2005.

3. Paget S: The distribution of secondary growths in cancer of the breast. Lancet 1: 571-573, 1889.

4. Chau I, Norman AR, Cunningham D, et al: Multivariate prognostic factor analysis in locally advanced and metastatic esophago-gastric cancer-pooled analysis from three multicenter, randomized, controlled trials using individual patient data. J Clin Oncol 22: 2395-2403, 2004.

5. Yashiro M, Chung YS, Nishimura S, Inoue T and Sowa M: Fibrosis in the peritoneum induced by scirrhous gastric cancer cells may act as 'soil' for peritoneal dissemination. Cancer 77 (Suppl 8): S1668-S1674, 1996.

6. Rieppi M, Vergani V, Gatto C,Zanetta G, Allavena P, Taraboletti G and Giavazzi R: Mesothelial cells induce the motility of human ovarian carcinoma cells. Int J Cancer 80: 303-307, 1999.

7. Takatsuki H, Komatsu S, Sano R, Takada Y and Tsuji T: Adhesion of gastric carcinoma cells to peritoneum mediated by $\alpha 3 \beta 1$ integrin (VLA-3). Cancer Res 64: 6065-6070, 2004.

8. Attisano L and Wrana JL: Signal transduction by members of the transforming growth factor-beta superfamily. Cytokine Growth Factor Rev 7: 327-339, 1996

9. Ihn H: Pathogenesis of fibrosis: role of TGF-beta and CTGF. Curr Opin Rheumatol 14: 681-685, 2002.

10. Inoue T, Chung YS, Yashiro M, Nishimura $S$, Hasuma T, Otani $S$ and Sowa M: Transforming growth factor- $\beta$ and hepatocyte growth factor produced by gastric fibroblasts stimulate the invasiveness of scirrhous gastric cancer cells. Jpn J Cancer Res 88: 152-159, 1997.

11. Lv ZD, Na D, Liu FN, Du ZM, Sun Z, Li Z, Ma XY, Wang ZN and $\mathrm{Xu}$ HM: Induction of gastric cancer cell adhesion through transforming growth factor-beta1-mediated peritoneal fibrosis. J Exp Clin Cancer Res 29: 139, 2010.

12. Koyama T, Yashiro M, Inoue T, Nishimura S, Hirakawa YS and Chung K: TGF-betal secreted by gastric fibroblasts up-regulates $\mathrm{CD} 44 \mathrm{H}$ expression and stimulates the peritoneal metastatic ability of scirrhous gastric cancer cells. Int J Oncol 16: 355-362, 2000. 
13. Komuro A, Yashiro M, Iwata C, Morishita Y, Johansson E, Matsumoto Y, Watanabe A, Aburatani H, Miyoshi H, Kiyono K, Shirai YT, Suzuki HI, Hirakawa K, Kano MR and Miyazono K: Diffuse-type gastric carcinoma: progression, angiogenesis, and transforming growth factor signaling. J Natl Cancer Inst 101: 592-604, 2009.

14. Mohammed KA, Nasreen N, Hardwick J, Van Horn RD, Sanders KL and Antony VB: Mycobacteria induces pleural mesothelial permeability by downregulating $\beta$-catenin expression. Lung 181: 57-66, 2003 .

15. Oravecz T, Pall M, Roderiquez G, Gorrell MD, Ditto M, Nguyen NY, Boykins R, Unsworth Eand Norcross MA: Regulation of the receptor specificity and function of the chemokine RANTES (regulated on activation, normal T cell expressed and secreted) by dipeptidyl peptidase IV (CD26)-mediated cleavage. J Exp Med 186: 1865-1872, 1997.

16. Alkhamesi NA,Ziprin P, Pfistermuller K, Peck DH and Darzi AW: ICAM-1 mediated peritoneal carcinomatosis, a target for therapeutic intervention. Clin Exp Metastasis 22: 449-459, 2005.

17. Hirashima Y, Kobayashi H, Suzuki M, Tanaka Y, Kanayama N and Terao T: Transforming growth factor- $\beta 1$ produced by ovarian cancer cell line HRA stimulates attachment and invasion through an up-regulation of plasminogen activator inhibitor type-1 in human peritoneal mesothelial cells. J Biol Chem 278: 26793-26802, 2003

18. Otsuji E, Kuriu Y, Okamoto K, Ochiai T, Ichikawa D, Hagiwara A, Yamagishi H: Outcome of surgical treatment for patients with scirrhous carcinoma of the stomach. Am J Surg 188: 327-332, 2004.

19. Roviello F, Marrelli D, Manzoni GD, Morgagni P, Leo AD, Saragoni L and Stefano AD: Prospective study of peritoneal recurrence after curative surgery for gastric cancer. Br J Surg 90: 1113-1119, 2003.

20. Ksiazek K, Mikula-Pietrasik J, Korybalska K, Dworacki G, Jörres A and Witowski J: Senescent peritoneal mesothelial cells promote ovarian cancer cell adhesion: the role of oxidative stress-induced fibronectin. Am J Pathol 174: 1231-1240, 2009.
21. Wierzbicka PL and Schwarzbauer JE: The ins and outs of fibronectin matrix assembly. J Cell Sci 116: 3269-3276, 2003.

22. Matsuoka T, Hirakawa K, Chung YS, Yashiro M, Nishimura S, Sawada T, Saiki I and Sowa M: Adhesion polypeptides are useful for the prevention of peritoneal dissemination of gastric cancer. Clin Exp Metastasis 16: 381-388, 1998.

23. Fujii H, Nishikawa N, Komazawa H, Suzuki M, Kojima M, Itoh I, Obata A, Ayukawa K, Azuma I and Saiki I: A new pseudopeptide of Arg-Gly-Asp (RGD) with inhibitory effect on tumor metastasis and enzymatic degradation of extracellular matrix. Clin Exp Metastasis 16: 94-104, 1998.

24. De Wever O, Demetter P, Mareel M and Bracke M: Stromal myofibroblasts are drivers of invasive cancer growth. Int J Cancer 123: 2229-2238, 2008.

25. Varga $\mathbf{J}$ and Pasche B: Transforming growth factor $\beta$ as a therapeutic target in systemic sclerosis. Nat Rev Rheumatol 5: 200-206, 2009.

26. Goumans MJ and Mummery C: Functional analysis of the TGFbeta receptor/Smad pathway through gene ablation in mice. Int J Dev Biol 44: 253-265, 2000 .

27. Itoh S and Ten Dijke P: Negative regulation of TGF-beta receptor/ Smad signal transduction. Curr Opin Cell Biol 19: 176-184, 2007.

28. Lv ZD, Na D, Ma XY, Zhao C, Zhao WJ and Xu HM: Human peritoneal mesothelial cell transformation into myofibroblasts in response to TGF- $\beta 1$ in vitro. Int J Mol Med 27: 187-193, 2011.

29. Moissoglu K and Schwartz MA: Integrin signaling in directed cell migration. Biol Cell 98: 547-555, 2006.

30. Yoshinaga IG, Vink J, Dekker SK, et al: Role of $\alpha 3 \beta 1$ and $\alpha 2 \beta 1$ integrins in melanoma cell migration. Melanoma Res 3: 435-441, 1993.

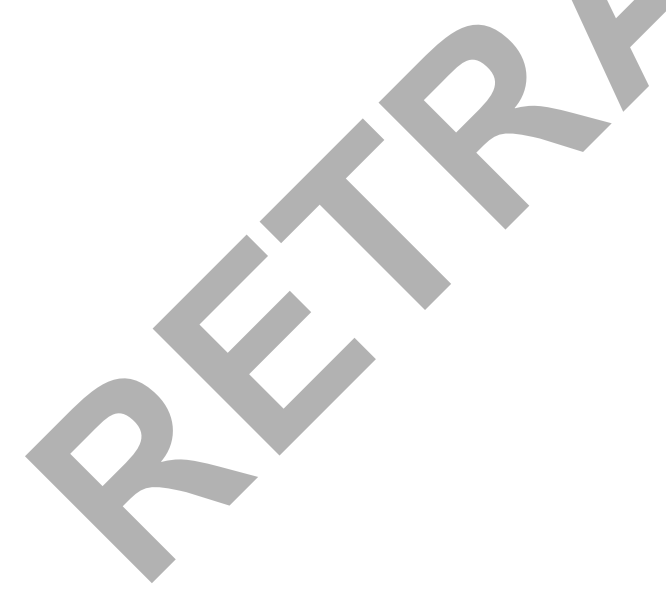

